\title{
INTERACTION OF HUMAN POLYMORPHONUCLEAR LEUKOCYTES WITH PSEUDOMONAS PSEUDOMALLEI
}

\author{
NYONYA RAZAK AND GHAZALLY ISMAIL*,1 \\ Universiti Pertanian Malaysia \\ Serdang, Selangor \\ * Faculty of Science and Natural Resources \\ Universiti Kebangsaan Malaysia \\ Sabah Campus \\ Kota Kinabalu \\ Sabah, Malaysia
}

(Received September 16, 1982)

The interaction of Pseudomonas pseudomallei with human polymorphonuclear leukocytes (PMNs) has been eamined. Human PMNs ingested $P$. pseudomallei after incubation for $60 \mathrm{~min}$ in the presence of normal serum. The bacteria were however relatively resistant to phagocytosis by human PMNs in the absence of serum or in the presence of heat-inactivated serum $\left(56^{\circ}\right.$ for $\left.30 \mathrm{~min}\right)$. Rapid intracellular killing of $P$. pseudomallei was observed in the presence of $10 \%$ normal human serum; but killing efficiency was reduced in the presence of heat-inactivated serum. Killing in the leukocyte bactericidal assay was shown to be predominantly due to the PMN bactericidal effect; not to the $10 \%$ normal serum contained in the incubation mixture. Ingestion of the bacteria was accompanied by a 2-fold stimulation of the hexose monophosphate pathway (HMP). In the absence of phagocytosis, however, the bacteria failed to show a marked enhancement in the HMP-shunt activity. Electron microscopic evidence showed that degranulation and bacterial morphologic changes occurred within $1 \mathrm{hr}$ after the organism was ingested. Our data suggest that human PMNs kill P. pseudomallei efficiently after ingestion of the organism in the presence of thermolabile serum opsonins. The occasional chronic nature of the disease caused by $P$. pseudomallei, therefore, could not be explained simply by the ability of the organism to survive within PMNs.

Pseudomonas pseudomallei causes meliodosis, an endemic glanders-like disease of humans and animals in Southeast Asia $(1,2)$. It is a common inhabitant of

\footnotetext{
1 To whom request for reprints should be addressed to.
} 
soil and water in endemic areas. The bacterium appears to be a free-living soil organism which causes infection when contaminated soil or water enters abrasions and lacerations of the skin.

The skin and mucous membranes provide highly effective anatomical, physiological and biochemical barriers to invasion by $P$. pseudomallei. When these barriers are breached, a hostile encounter between bacteria and the host occurs and one of the first host factors involved in this encounter is the phagocytic leukocytes (3). Polymorphonuclear leukocytes (PMN) constitute an important line of defense against bacterial infection (4). The host is stimulated to generate a more generalized inflammatory response and PMNs in large numbers are attracted to the site. The capacity of these leukocytes to efficiently ingest and kill invading bacteria at the primary foci of infection is the crucial factor in preventing the dissemination of the organism.

This phase of the inflammatory response, i.e., the response of human PMNs to infection by $P$. pseudomallei is the subject of our present investigation. We chose to examine the interaction of the bacteria with PMN's for two reasons: (i) the PMN is likely the first phagocyte which the bacteria encounter, especially if the infection occurs through a cut, and (ii) it was of interest to ascertain whether the disease in its chronic state, rarely caused by $P$. pseudomallei, relates to the ability of the organism to resist killing by phagocytes and survive intracellularly.

\section{MATERIALS AND METHODS}

Source of PMN. Venous blood was drawn from normal adult volunteers and the leukocytes were separated by sedimentation of the erythrocytes at $37^{\circ}$ with $6 \%$ dextran. The leukocyte-rich plasma was centrifuged at $250 \times g$ for $10 \mathrm{~min}$ at $4^{\circ}$ and the cells were resuspended in $0.2 \% \mathrm{NaCl}$ for $20 \mathrm{sec}$ to lyse the erythrocytes; isotonicity was restored with an equal volume of $1.6 \% \mathrm{NaCl}$. The cells were washed twice and resuspended in Krebs Ringer Phosphate solution (KRP), pH 7.4. Viability studies using trypan blue exclusion tests consistently revealed greater than $90 \%$ viability of the PMN suspensions. The cells were adjusted to give a final suspension of $2 \times 10^{6} \mathrm{PMN} / \mathrm{ml}$.

Bacteria. P. pseudomallei used in this study was provided by the Microbiology Department, Faculty of Medicine, Universiti Kebangsaan Malaysia, Kuala Lumpur. Cells were routinely propagated on Brain Heart Infusion Agar (BHIA) at $37^{\circ}$. For most tests with $P$. pseudomallei, $18 \mathrm{hr}$ exponential phase broth cultures containing about $1.5 \times 10^{7}$ bacteria/ml were used.

Phagocytosis. The PMN suspension $(0.5 \mathrm{ml})$ and the bacterial suspension $(0.5 \mathrm{ml})$ were mixed in a series of siliconized tubes to give a phagocyte/bacteria ratio of approximately $1 / 10$. Control tubes contained bacterial suspensions $(0.5$ $\mathrm{ml})$ and KRP $(0.5 \mathrm{ml})$ but no PMN. In tubes containing $0.1 \mathrm{ml}$ normal serum of heat-inactivated serum $\left(56^{\circ}\right.$ for $30 \mathrm{~min}$ ), the volume of bacterial and PMN suspen- 
sions were each reduced to $0.45 \mathrm{ml}$. The tubes were shaken in a $37^{\circ}$ water bath and at time intervals of $0,15,30$ and $60 \mathrm{~min}$, samples were taken for the assessment of ingestion rate and bactericidal activity of PMN.

a) Assessment of ingestion rate. At each time interval of 0,15,30 and $60 \mathrm{~min}$, a $20 \mu 1$ sample was withdrawn. Thin smears were prepared on glass slides and stained with Wright stain. The smears were carefully examined microscopically under oil immersion objective to determine the number of bacteria ingested by PMN at each time interval. The bacteria that were counted were (i) morphologically typical of $P$. pseudomallei, (ii) in the focal plane of the nucleus of the PMN and (iii) within the PMN cell border. Bacteria adjacent to the PMN or not meeting all of these criteria were not counted. Results were expressed as the number of bacteria in $100 \mathrm{PMN}$ at $0,15,30$ and 60 min time intervals. Coded slides were assessed periodically and the results agreed with those of other experiments with the same parameters.

b) Assessment of PMN bactericidal activity. Samples of $0.1 \mathrm{ml}$ were taken from the incubation tubes at $0,15,30$ and $60 \mathrm{~min}$ time intervals. The PMNs were lysed in $0.9 \mathrm{ml}$ of ice-cold distilled water with vortex shaking for $1 \mathrm{~min}$ and appropriate dilutions were used for agar pour plates.

Serum bactericidal activity. To test the serum-dependent killing system in the absence of PMN, tubes containing $0.1 \mathrm{ml}$ of bacterial suspension $\left(10^{7}\right.$ cells/ $\mathrm{ml}), 0.8 \mathrm{ml}$ of phosphate-buffered saline (PBS) and $0.1 \mathrm{ml}$ of the appropriate serum dilutions were incubated at $37^{\circ}$ in a shaking water bath for $2 \mathrm{hr}$. Control tubes contained organisms suspended in PBS alone. Triplicate $0.1 \mathrm{ml}$ samples were wtihdrawn at 0,30,60 and 120 min time intervals for plating on BHIA. The colonyforming units (CFU) were enumerated after $18 \mathrm{hr}$ incubation.

Measurement of glucose- $1-{ }^{14} \mathrm{C}$ oxidation. The activity of hexose-monophosphate shunt (HMP) was determined as previously described (5). Briefly, the incubation mixture contained in a final volume of $1.0 \mathrm{ml}, 1.5 \times 10^{6} \mathrm{PMN}$, glucose$1-{ }^{14} \mathrm{C}$, KRP and $1.0 \times 10^{6}$ bacteria. The negative controls contained no bacteria and were appropriately adjusted to $1.0 \mathrm{ml}$ final volume with KRP. The effect of serum and P. pseudomallei on the HMP pathway of PMNs was investigated by the addition of $0.1 \mathrm{ml}$ normal or immune serum to the incubation mixture. Tubes were incubated in a shaking water bath at $37^{\circ}$ for $30 \mathrm{~min}$. To stop the reaction, $0.2 \mathrm{ml} \mathrm{H}_{2} \mathrm{SO}_{4}$ was added and the incubation was continued for an additional $30 \mathrm{~min}$. Filter papers soaked in $0.2 \mathrm{ml}$ of methyl benzethonium hydroxide to absorb ${ }^{14} \mathrm{CO}_{2}$ were counted by liquid scintillation. Each experiment was donein duplicate and the results were averaged.

Electron microscopy. The incubated mixture was centrifuged at $300 \times g$ for 10 min. The pellet was resuspended in PBS, $\mathrm{pH} 7.4$; a drop of the preparation was then placed on a grid and stained with phosphotungstic acid. The film was dried and the grid was examined under transmisssion electron microscope (Phillips 400). 


\section{RESULTS}

Phagocytosis of P. pseudomallei

The results of the interaction of $P$. pseudomallei and the human PMN leukocytes were evaluated by examining coverslips stained at 15, 30 and 60 min time intervals. The extent of phagocytosis of $P$. pseudomallei by human leukocytes is indicated in Fig. 1. The results of experiments showed that the number of bacteria ingested by PMN leukocytes was low when incubated in the absence of serum. Even after incubation of $1 \mathrm{hr}$ without serum, $P$. pseudomallei was not readily ingested by human leukocytes (i.e. $<100$ bacteria). Visual counts of the ingested bacteria in experiments where heat-inactivated serum $\left(56^{\circ}\right.$ for $\left.30 \mathrm{~min}\right)$ was added to the phagocytic mixture also indicated that $P$. pseudomalle $i$ was relatively resistant to phagocytosis by human PMN leukocytes. There was no obvious difference between the ingestion rate of $P$. pseudomallei by PMNs in the absence of serum and in the presence of heat-inactivated serum. There was a pronounced difference, however, in the number of $P$. pseudomallei ingested by PMNs (i.e. $>$ 600 bacteria after $1 \mathrm{hr}$ incubation )in the presence of normal serum.

\section{Killing of P. pseudomallei by human PMN}

In the present investigation, one purpose was to study the intraleukocytic fate of the ingested $P$. pseudomallei. The results of a representative experiment to

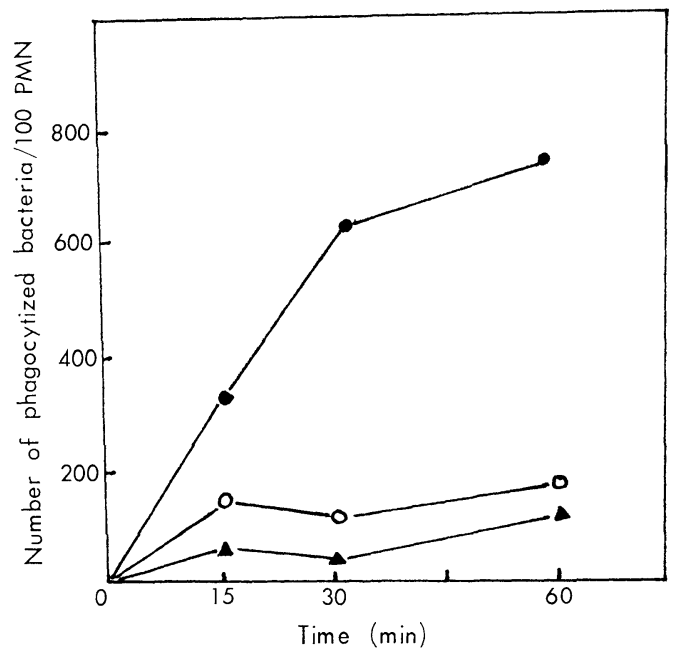

Fig. 1. Phagocytosis of Pseudomonas pseudomallei by human polymorphonuclear leukocytes (PMN).

$\boldsymbol{\Delta}$, bacteria $+\mathrm{PMN} ; \mathrm{O}$, bacteria $+\mathrm{PMN}+$ heat-inactivated serum; $\bullet$, bacteria $+\mathrm{PMN}$ + normal serum. 


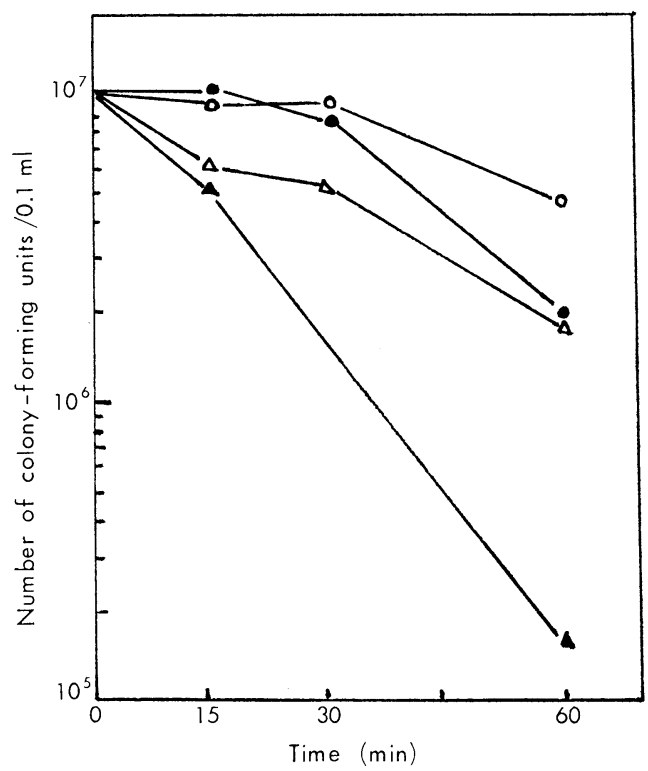

Fig. 2. Killing of Pseudomonas pseudomallei by polymorphonuclear leukocytes.

$\bigcirc$, bacteria alone; $\bullet$, bacteria $+\mathrm{PMN} ; \triangle$, bacteria + heat-inactivated serum; $\Delta$, bacteria + normal serum.

assess the killing of $P$. pseudomallei by human leukocytes are shown in Fig. 2. In the presence of $10 \%$ normal human serum, the bacteria were killed efficiently by PMNs, i.e. a 2-log reduction in the number of viable bacteria in $60 \mathrm{~min}$ of incubation. Rapid intracellular bactericidal effect on the organism was evident as early as 15 min after incubation started. The killing effect of PMN leukocytes was, however, less efficient in the presence of heat-inactivated serum. The counts of surviving bacteria incubated with PMN leukocytes alone, after $1 \mathrm{hr}$ incubation, showed no significant difference from the counts obtained from the tubes containing bacteria alone.

\section{Effect of human serum on P. pseudomallei}

The results of typical serum bactericidal tests are shown in Fig. 3. Normal human serum incubated with $P$. pseudomallei for $2 \mathrm{hr}$ displayed no considerable bactericidal activity. The viability count of the bacteria, however, was reduced slightly to approximately $50 \%$ after $1 \mathrm{hr}$ of incubation with $30 \%$ normal human serum. The results described show that $P$. pseudomallei are not highly susceptible to the action of human normal serum, indicating that the reduction of CFU in the leukocytic killing assay is predominantly due to intraleukocidal mechanisms, not to the $10 \%$ normal human serum added to the incubation mixture. 


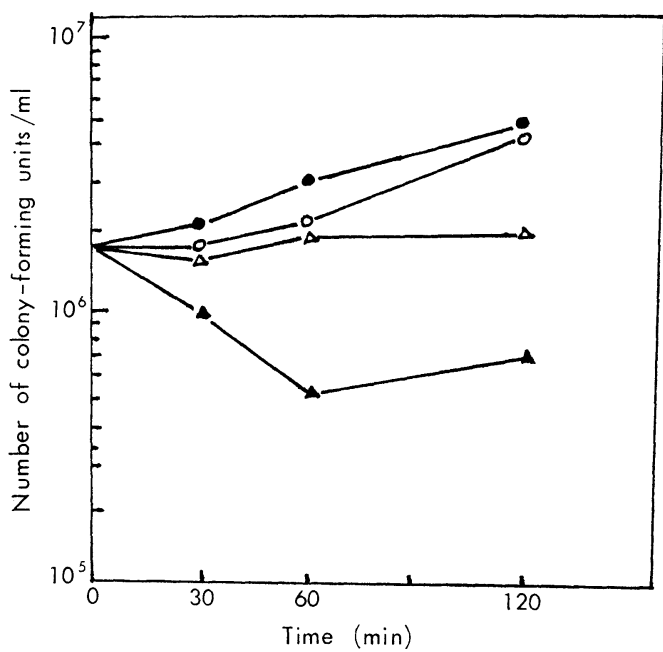

Fig. 3. The effect of different concentrations of human normal serum on the viability of Pseudomonas pseudomallei.

O, no serum; •, $10 \%$ serum; $\triangle, 20 \%$ serum; $\Delta, 30 \%$ serum.

Table 1. Release of labelled carbon dioxide during phagocytosis of Pseudomonas pseudomallei by hunam PMN leukocytes.

Conditions of experiments

Bacteria alone (Control)

Bacteria + normal serum (Control)

WBC alone (Control)

$\mathrm{WBC}+$ normal serum (Control)

WBC + bactera + normal serum

$\mathrm{WBC}+$ bacteria + heat-inactivated serum

$\mathrm{WBC}+$ bacteria + immune serum

WBC + bacteria + cytochalasin B $(10 \mu \mathrm{g} / \mathrm{ml})$
Counts per min (mean \pm SEM)

$$
\begin{array}{r}
210 \pm 5.72 \\
232 \pm 6.82 \\
661 \pm 8.81 \\
708 \pm 6.88 \\
1,426 \pm 34.59 \\
992 \pm 26.98 \\
2,070 \pm 59.57 \\
1,154 \pm 51.65
\end{array}
$$

Each set of experiment were done in triplicate.

Stimulation of the HMP pathway during phagocytosis of P. pseudomallei

Measurement of the extent of glucose- $1-{ }^{14} \mathrm{C}$ oxidation by PMN leukocytes provided an indication of the bactericidal potential of the phagocytic cell (6). As shown in Table 1, there was approximately a 2 -fold increase in the stimulation of the HMP pathway in PMNs exposed to P.pseudomallei in the presence of normal human serum. Incubation with hyperimmune serum further stimulated the HMP pathway in PMNs 3.5-fold. There was a slight increase $(50 \%)$ of HMP pathway stimulation when the organism was incubated with PMN's in the presence of heat-inactivated serum. One explanation for the observed modest stimulation of the HMP pathway in the presence of heat-inactivated serum was the loss of serum 


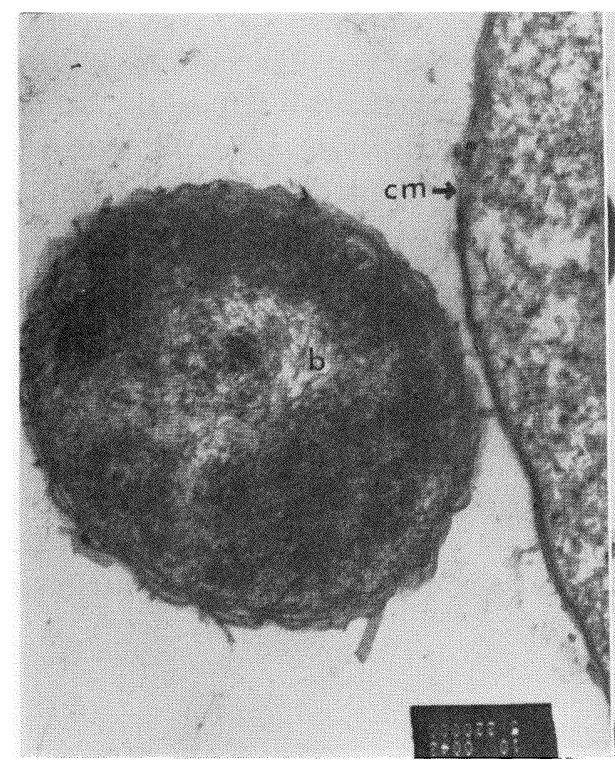

A

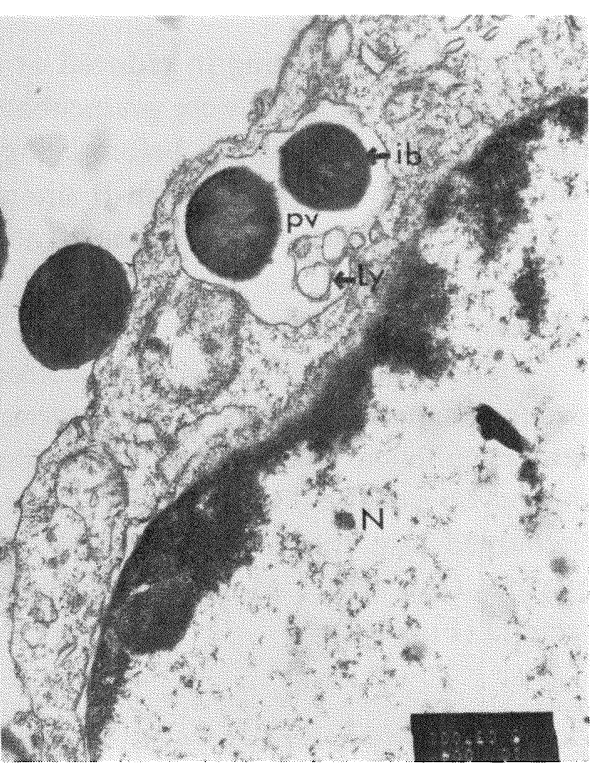

B

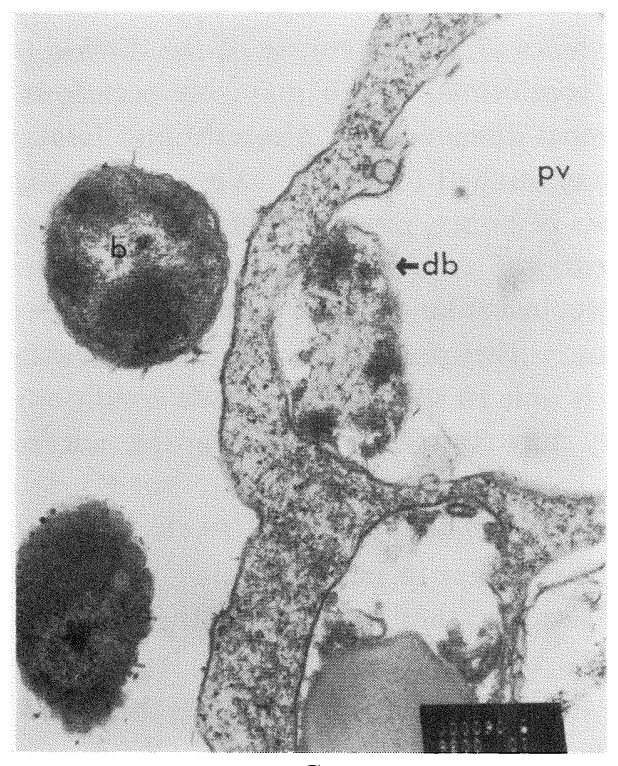

\section{C}

Fig. 4. Electron micrograph showing the interaction of $P$. pseudomallei with a human polymorphonuclear leukocyte in the presence of normal serum.

(A) an encounter between $P$. pseudomallei and the surface of the leukocyte (magnification $\times 165,000$ ); (B) the bacteria in phagocytic vacuole and discharge of lysosomes into the vacuole (magnification $\times 27,750$ ); (C) the morphologic changes occurring in the ingested bacterium within the phagocytic vacuole (magnification $\times 45,000$ ). $b=$ bacterium, $\mathrm{cm}=$ leukocyte membrane, $\mathrm{N}=$ nucleus, $\mathrm{pv}=$ phagocytic vacuole, $\mathrm{ib}=$ intact bacterium, Ly $=$ lysosome, $\mathrm{db}=$ disintegrating bacterium. 
opsonic activity resulting in reduced or no ingestion of the organisms by PMNs. To test this, the PMNs were preincubated with cytochalasin-B $(10 \mu \mathrm{g} / \mathrm{ml})$, an inhibitor of phagocytosis (7), before being exposed to $P$. pseudomallei. Preincubation of PMNs with cytochalasin-B stimulated the HMP pathway to a comparable degree to that caused by heat-inactivated serum, i.e., app. $50 \%$.

\section{Electron microscopy}

Figure $4 \mathrm{~A}$ demonstrates by electron micrography an encounter between $P$. pseudomallei and the surface of a normal human PMN leukocyte. The bacteria were engulfed as the leukocyte membrane surrounded the particles forming a phagocytic vacuole; and the leukocyte cytoplasmic lysosomes appeared to be discharged into the vacuole so that the vacuole contained activated hydrolytic enzymes (Fig. 4B). Morphologic changes rapidly occurred in the intracellular bacteria (Fig. 4C).

\section{DISCUSSION}

$P$. pseudomallei produces a glanders-like disease which is fatal in approximately $95 \%$ of cases within several days to four weeks (8). The course of the disease is that of a progressive and overwhelming septicemia, which may, on occasions, cause death within $24 \mathrm{hr}(\mathrm{l})$. Although most disseminated infections end fatally in a matter of days or weeks, a few have continued for years. Very rarely, the disease may be chronic with multiple lesions of bones, joints and lungs resembling tuberculosis $(9,10)$. The intracellular survical of Mycobacterium tuberculosis within phagocytes contributes to the tuberculosis-like chronicity and complicates chemotherapeutic approaches to the disease. Therefore, it was quite conceivable that, like $M$. tuberculosis, $P$. pseudomallei is able to survive the hostile conditions within phagocytic vacuoles and this ability may contribute to the chronic nature of the infection.

Our study of the interaction of P. pseudomallei with human PMNs showed that the untreated organisms were relatively resistant to phagocytosis. However, once opsonized by heat-labile serum components, they were avidly ingested and killed.

The viability of ingested $P$. pseudomallei was examined by assaying the reduction in CFU of the organisms after incubation with human PMNs. Our results showed killing rates of $87-92 \%$ within $30 \mathrm{~min}$. This killing rate did not support the contention that $P$. pseudomallei are resistant to the bactericidal mechanisms of human PMNs. In fact, the reduction in CFU of $P$. pseudomallei was comparable to other extracellular bacteria like Escherichia coli, Staphyloccocus aureus and Bacillus subtilis where $99 \%$ were rendered non-viable after about $20 \mathrm{~min}$ incubation with PMNs or macrophages (11).

Intracellular parasites may display three possible mecahnisms to survive 
within the phagocytic vacuoles: (i) resistance to the bactericidal agents generated in the phagolysosomes; (ii) inhibition of the HMP pathway stimualtion, a specific sequence of events after ingestion which would normally be bactericidal (12) and (iii) inhibition of lysosomal fusion with the phagocytic vacuoles (13). HMP pathway stimulation was not observed when the leukocytes were incubated with normal serum in the absence of bacteria. But stimulation of the HMP pathway was observed in PMNs after ingestion of $P$. pseudomallei. Similarly, electron microscopic evidence suggested that degranulation after ingestion of the organism by PMNs does occur and that the ingested cells are destroyed within an hour after phagocytosis. The data presented here clearly demonstrates that human PMN leukocytes are capable of destroying $P$. pseudomallei. Thus our early supposition that the occasional chronic nature of disease caused by $P$. pseudomalle $i$ could be explained simply by the ability of the organism to survive within leukocytes was not correct.

Our in vitro studies indicate that the organism is ingested in the presence of non-specific thermolabile opsonins. However, it is not clear whether phagocytosis of the organisms is similarly facilitated in vivo. Previous investigations with E. coli, Staphylococcus aureus, Streptococcus pyogenes and Diplococcus pneumoniae (14-17) showed that these bacteria produce surface anti-phagocytic components in vivo that contribute to increased pathogenecity. To date, little work has been done on the surface components of $P$. pseudomallei and subsequently little is known about the virulence factors of the organism.

We gratefully acknowledge the kind cooperation of the Laboratory Staff, Microbiology Department, Faculty of Life Sciences, Universiti Kebangsaan Malaysia. We thank Dr. Mohamed Omar and Mr. Megat Razi for their skillful assistance with the electron microscopy and Mrs. Mohd Ghazali for typing the manuscript.

\section{REFERENCES}

1) A. Whitmore, J. Hyg. (Cam.), 13, 1 (1913).

2) A. Whitmore and C. S. Krishnawami, Ind. Med. Gas., 47, 262 (1912).

3) J. W. Rebuck and J. H. Crowley, Ann. N.Y. Acad. Sci., 59, 757 (1961).

4) T. P. Stossel, N. Engl. J. Med., 290, 717, 774 (1974).

5) R. L. Baehner, N. Gilman and M. L. Karnovsky, J. Clin. Invest., 162, 1277 (1970).

6) C. R. De Chatelet, J. Infect. Dis., 131, 295 (1975).

7) S. E. Malawista, J. B. L. Gee and K. G. Beusch, Yale J. Biol. Med., 44, 286 (1971).

8) W. Topley and G. Wilson, Principles of Bacteriology and Immunity, Williams and Wilkins, Baltimore (1946), p. 492.

9) J. Mayer, J. Bone J. Surq., xxvii, 49 (1945).

10) A. Grant and C. Barwell, Lancet, i, 199 (1943).

11) A. Z. CoHn, J. Exp. Med., 117, 27 (1963).

12) D. L. Kreutzer, L. A. Dreyfus and D. C. Robertson, Infect. Immun., 23, 737 (1979).

13) M. B. Goren, P. D. Hart, M. R. Young and J. A. Armstrong, Proc. Natl. Acad. Sci. USA., 73, 2510 (1976).

14) F. Orskov, J. Infect. Dis., 137, 630 (1978). 
15) P. K. Peterson, B. J. Wilkinson, Y. Kim, D. Schmeling, S. D. Douglas and P. G. Quie, J. Clin. Invest., 61, 597 (1978).

16) S. S. Barkulis, Ann. N. Y. Acad. Sci., 88, 1034 (1960).

17) J. F. Enders, M. F. Shaffer, C. J. Wu, J. Exp. Med., 64, 307 (1936). 